\title{
High-speed video observation of lightning flashes over Johannesburg, South Africa 2017 - 2018
}

\author{
Carina Schumann \\ School of Electrical and Information \\ Engineering \\ University of the Witwatersrand \\ Johannesburg, South Africa \\ Email: carina.schumann@wits.ac.za
}

\author{
Hugh.G.P. Hunt \\ School of Electrical and Information \\ Engineering \\ University of the Witwatersrand \\ Johannesburg, South Africa \\ Email: hugh.hunt@wits.ac.za
}

\author{
Ken J. Nixon \\ School of Electrical and Information \\ Engineering \\ University of the Witwatersrand \\ Johannesburg, South Africa \\ Email: ken.nixon@wits.ac.za \\ Marcelo M.F. Saba \\ Atmospheric Electricity Group \\ Brazilian National Institute for Space \\ Research \\ São José dos Campos, Brazil \\ Email: marcelo.saba@inpe.br
}

\author{
Jesse Tasman \\ School of Electrical and Information \\ Engineering \\ University of the Witwatersrand \\ Johannesburg, South Africa
}

\author{
Tom A. Warner \\ ZT Research, \\ Rapid City, USA \\ Email: tom.warner@ztresearch.com
}

Abstract - South Africa has a long history of lightning research. Tall towers provide a useful tool for investigating lightning as they generally have a high repeatability of events. The Johannesburg region in the Gauteng province has two tall towers, the Brixton tower and the Hillbrow tower, with a high frequency of lightning events. This paper presents a project beginning in January 2017 and aims to study the physics of lightning through high-speed video observation and fast electric field measurements. Thunderstorms over Johannesburg have a high cloud base which allows for visible channels from the tall towers. More than 200 videos of downward and upward flashes were observed since the project started. Also, 6 flashes to a $53 \mathrm{~m}$ tall building were observed. The project also aims to raise awareness around lightning dangers in Africa.

Keywords- South African lightning; high-speed camera; upward lightning; downward lightning

\section{INTRODUCTION}

South Africa has a long history of research into lightning to tall structures $[1,2]$. The purpose of this paper is to present a project that is to be undertaken in 2017-2018. This is a scientific project that aims to investigate the physics of lightning by high-speed video observation along with electric field measurements and potential current measurements as well in Johannesburg, South Africa. It is part of an international collaboration between Brazil, USA, Austria and Sweden. Historically, these are all locations where tall tower investigations of lightning have been performed (using highspeed camera observations, electric field measurements, current measurements or a combination of these). Tall towers provide a useful tool for investigating lightning as they generally have a high repeatability of events. The Johannesburg region has two tall towers, the Brixton tower and the Hillbrow tower, with a high frequency of lightning events. However, these events are usually upward in nature, and an investigation of the density of lightning over Johannesburg to determine other, less tall locations is considered.

\section{JOHANNESBURG, SOUTH AFriCA}

Johannesburg is the main economic city in South Africa and can be found in the north-east of the country. It is the location of much of the industry in South Africa. It is also notable for its altitude - approximately $1600 \mathrm{~m}$ above sea level. Figure 1 shows the skyline of Johannesburg. 


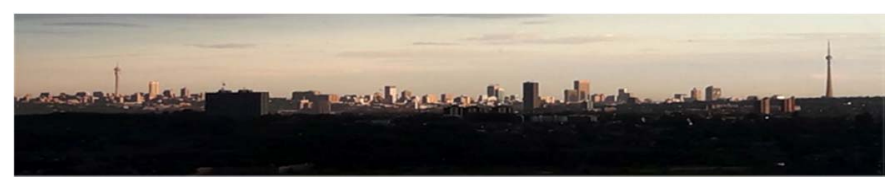

Figure 1. The skyline of Johannesburg city, view from the north looking south through the city.

This photograph is taken from the north facing south through the city. Two tall towers on either ends of the skyline can be seen. These are the Brixton (right) and Hillbrow (left) tower. The Brixton tower is west of the city and Hillbrow tower is east. Figure 2 is a sketch of the height, and distance between the towers.

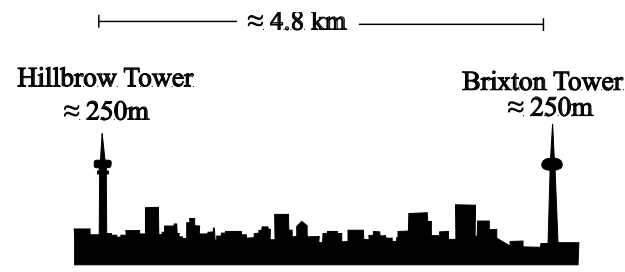

Figure 2. The two tall towers in Johannesburg city, Brixton (right) and Hillbrow (left) tower.

While these are the two tallest buildings, a number of other locations and buildings of interest fall within the city. The University of the Witwatersrand is located approximately halfway between the Brixton and Hillbrow tower.

Figure 3 shows the lightning flash density map of South Africa as of 2014. This map was created by the South African Weather Service (SAWS) utilizing data from the South African Lightning Detection Network (SALDN) - the lightning location system in operation in South Africa.

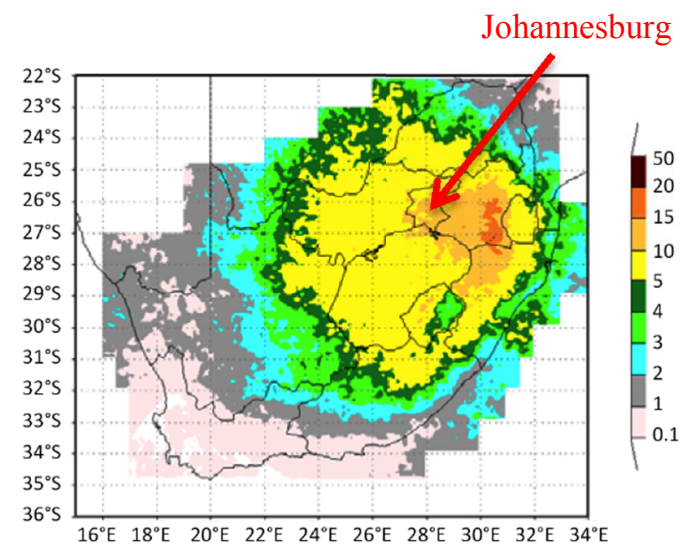

Figure 3. Lightning flash density over South Africa. Image used with permission, courtesy Morné Gijben [3]. The location of Johannesburg is indicated.

The SALDN consists of 25 Vaisala LS7000 sensors located across the country (with one sensor located in Swaziland) and has been operational since 2006. SAWS has collected more than 10 years worth of lightning data over the whole country. The network has an estimated average detection efficiency of 90\% and approximately $500 \mathrm{~m}$ median location accuracy.
As can be seen in figure 3 , the areas of highest lightning flash density are to the north-east of the country, in region known as the Mpumalanga province. Johannesburg is located close to this region (indicated in the figure), not quite in the highest flash density region but still high with approximately 10-15 flashes $/ \mathrm{km}^{2} /$ year. The combination of the tall towers, altitude, cloud base and high flash density make Johannesburg a unique and relevant choice for lightning studies.

\section{A. Lightning Occurrence over Johannesburg}

Utilizing Gaussian smoothing techniques, lightning location system data can be further interrogated for more detail. Gaussian smoothing techniques utilize the confidence ellipses of stroke reports to represent a stroke as a distribution rather than a single point. In this way, it is possible to create flash density maps that are independent of resolution - ideal for looking at areas smaller than $10 \times 10 \mathrm{~km}$. Given that each attachment point has been "spread out" and is rather represented as a fraction over the grid, no actual values can be attributed to the values but visual density trends are clearly displayed.

Figure 4 shows a Gaussian smoothed map over Johannesburg city. The map utilizes data from the SALDN from $2007-2015$. The locations of the Brixton tower and the Hillbrow tower are shown. As is clear in the figure, there is a high density around the location of the two towers indicating that they are regularly struck - and much more than other locations within the city.

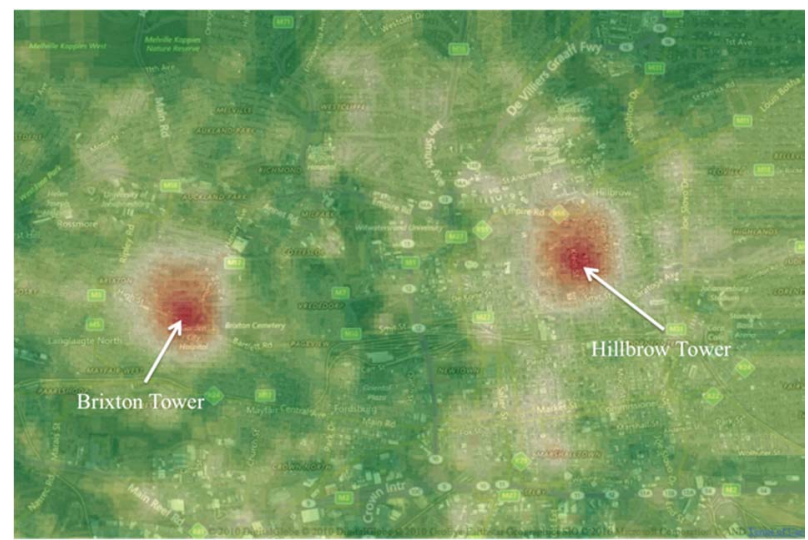

Figure 4. Gaussian smoothed lightning density map based on SALDN data from 2007 - 2015. The Brixton and Hillbrow towers are indicated in the image and can be distinguished by the "hotspots".

Gaussian smoothed maps can be used to investigate even further - figure 5 shows a similar image but only over the University of the Witwatersrand campus, located roughly in the city center about half-way between the Brixton and the Hillbrow tower. 


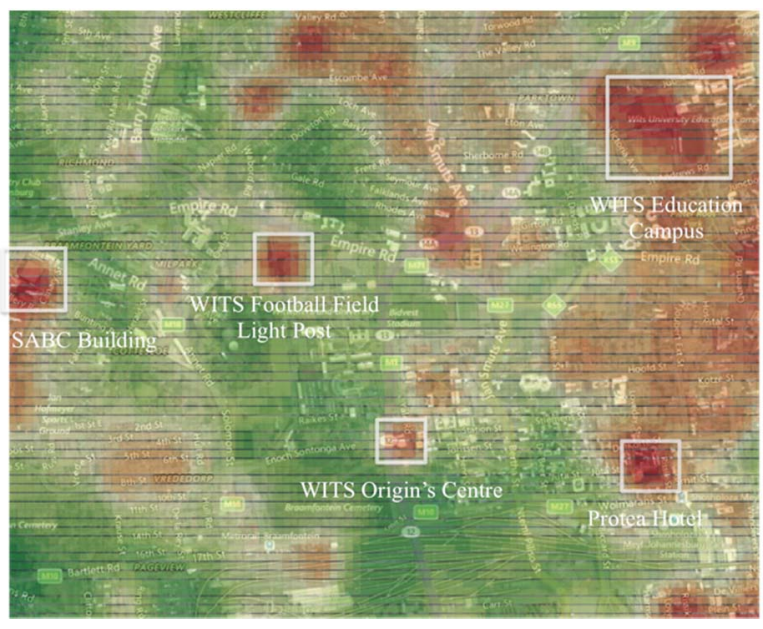

Figure 5. Gaussian smoothed lightning density map over Johannesburg, WITS University campus.

By examining the smaller area and excluding the Brixton and Hillbrow tower, more detail can be gained on specific locations around the city center and campus. It can be seen in the Figure 5 that there are a number of locations that seem to have been struck multiple times in the last 10 years. Five locations are identified on the map:

- $\quad$ The SABC broadcasting buildings

- A light post on a WITS football field

- $\quad$ The Origins Centre building on WITS campus

- The Protea Hotel in Braamfontein, Johannesburg

- $\quad$ The WITS Education Campus

None of these locations are significantly tall towers and it is very likely that the events they have endured are downward lightning events. The SABC broadcasting buildings, while close to the Brixton tower is sufficiently far away $(1 \mathrm{~km})$ so as not to be protected by the Brixton tower. Also of interest, is the Protea hotel in the Braamfontein area, a dense city area and yet, the Protea hotel clearly is struck fairly regularly, likely due to its height.

\section{B. Previous Photographic Studies}

Since 2009, a simple surveillance system to photograph lightning attachments to the Brixton tower was in operation. The system was initially installed to capture lightning images for 3-dimensional modeling of the lightning channel but was later used as a ground-truth location for comparison with the SALDN. The system consisted of a simple motion-triggered camera located at the University of the Witwatersrand and looking east towards the Brixton tower with an approximate field of view of $55^{\circ}$ [4]

The system initially operated from 2009-2013 but was shutdown in 2014. It was reinitiated in 2015 with a second camera added looking at the tower from a different perspective. Figure 6(a) and (b) shows an example of the type of images captured by the system - a lightning flash attaching to the
Brixton tower on Friday, 20 November 2015 at 22:24:48 SAST.

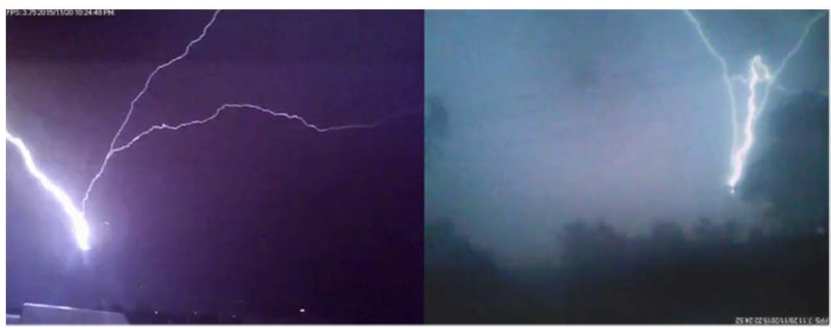

(a)

(b)

Figure 6. A lightning strike to the Brixton tower on the 20 November 2015 at 22:24:48 SAST. Two cameras observe the Brixton tower - (a) one situated at WITS university and facing east, (b) the other situated $1 \mathrm{~km}$ north of the tower and facing south.

Table 1 shows the number of flashes to the Brixton tower photographed by the camera for each season since 2009. The cases are separated between upward flashes and downward flashes and, as expected, the majority of flashes to the tower are upward. However, some downward events do also attach to the tower.

\section{TABLE I. PHOTOGRAPHED Flashes TO BRIXTON TOWER}

\begin{tabular}{|c|c|c|c|}
\hline Season & $\begin{array}{c}\text { Number } \\
\text { Upward } \\
\text { Flashes }\end{array}$ & $\begin{array}{c}\text { Number } \\
\text { Downward } \\
\text { Flashes }\end{array}$ & $\begin{array}{c}\text { Total } \\
\text { Number } \\
\text { Flashes }\end{array}$ \\
\hline $2009-2010$ & 12 & 0 & 12 \\
\hline $2010-2011$ & 24 & 2 & 26 \\
\hline $2011-2012$ & 6 & 1 & 7 \\
\hline $2012-2013$ & 17 & 4 & 21 \\
\hline $2015-2016$ & 46 & 9 & 55 \\
\hline Total & 105 & 16 & 121 \\
\hline
\end{tabular}

Also notable in the photographs is the clarity of the channel - the cloud base is far above the top of the tower allowing for a complete view of the channel, unlike many other tall towers in the world, which find themselves reaching into the clouds and therefore obscuring the visibility of any lightning events that may attach to them.

\section{HIGH-SPEED VIDEO STUDY}

Before Abbreviations and Acronyms

\section{A. Collaborators}

The project has a number of collaborators who assist both with equipment and experience: ZT Research in South Dakota, USA and INPE in São Paulo, Brazil have performed similar studies in their respective countries and SAWS and EarthNetworks operate lightning location systems. This section details the nature of the projects performed by these collaborators and highlights how their knowledge and results feed into the South African project.

\section{1) ZT Research}

Tom Warner, of ZT Research, has worked with high-speed cameras since 2010 in Rapid City, USA. The city has 10 towers that produce upward lightning [5]. Figure 7 shows a frame from a high-speed video, which captured upward 
lightning events from towers in Rapid City. The researchers spent four summers recording flashes in Rapid City along with electric field measurements provided the Brazilian National Institute for Space Research (INPE). Tom Warner lent two high-speed cameras (10,000 and 1,000 frames per second) to the project in South Africa and is involved in all research analysis.

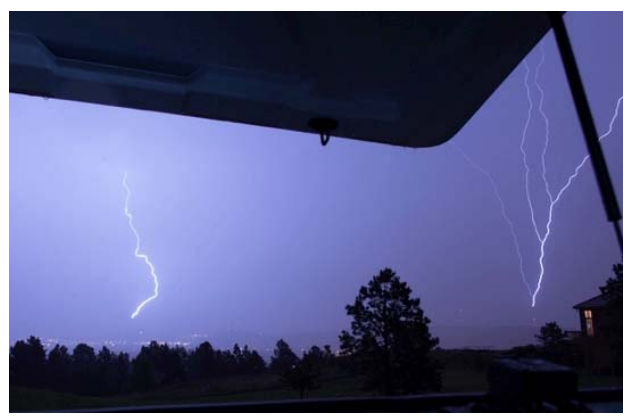

Figure 7. Upward lightning from towers in Rapid City, South Dakota.

\section{2) Brazilian National Institute of Space Research (INPE)}

The INPE team has experience with high-speed cameras and flat plate electric field measurements since 2003, and are pioneers on the characterization of the different polarities of flashes by images [6-7]. The team are have lent a flat plate electric field sensor, able to record data continuously at $5 \mathrm{MSamples} / \mathrm{s}$ to the South African project. Collaboration and comparison with ongoing research in São Paulo, Brazil (upward lightning to Jaraguá peak and downward lightning to normal apartment buildings) allows for comparison between data sets.

\section{3) $S A W S$}

SAWS has a long-standing agreement with the research group regarding the use of the SALDN data. The data provides insight into the filmed high-speed cases and simultaneously the video observation provide and ideal ground-truth data set for comparison with SALDN stroke detections and reports.

\section{4) EarthNetworks}

EarthNetworks have recently begun implementing a lightning location system in South Africa and similarly, there is value in comparing high-speed video observations with reports from such a network.

\section{B. Equipment and Experimental Setup}

The two high-speed cameras provided by ZT Research and being used for the study are the Phantom v310, Phantom v7.1. In general, the v310 records at approximately $15000 \mathrm{fps}$ with an exposure time of $58 \mu \mathrm{s}$ and the v7.1 at $5000 \mathrm{fps}$ with an exposure time of $990 \mu \mathrm{s}$. The different frame rates of the cameras and their subsequent exposure times and resolution allow for each recorded flash to be separately analysed. analysed separately - optimising the accuracy of the characterization process.

Figure 8 shows where the two high-speed cameras are located - an area north-west of the Johannesburg city center on a ridge known as Northcliff hill - along with the locations of the Brixton and the Hillbrow tower, and the city center between them. The camera view over the city is therefore the same as shown in figure 1, the skyline of Johannesburg.

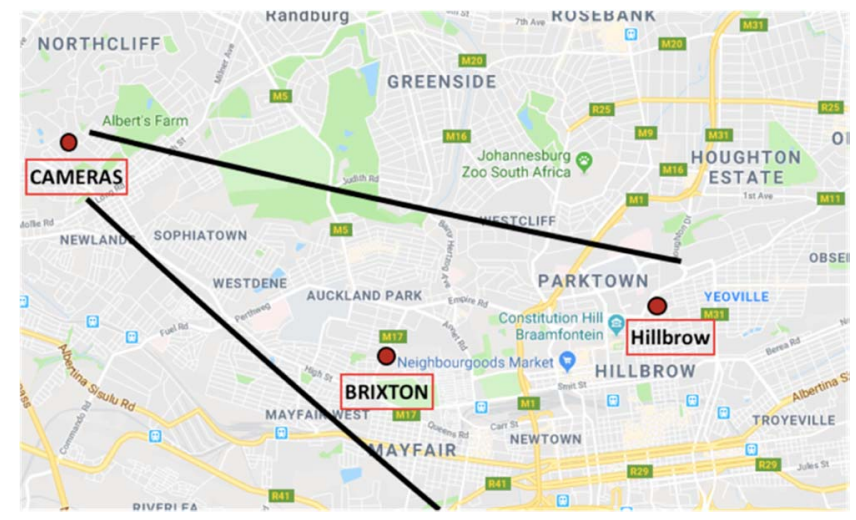

Figure 8. Location of high-speed cameras and the Brixton and Hillbrow towers, indicating Johannesburg city.

Also shown in figure 8 the locations of a number of simple surveillance camera setups similar to those used in the previous photographic study. However, here cameras located at the University of the Witwatersrand look not only to the Brixton tower but also at the Hillbrow tower and the city centre. Another on of these camera setups is located on the $52^{\text {nd }}$ floor of a building known as Ponte, a tall apartment building in the city not far from the Hillbrow tower. Figure 9 shows a photograph of a lightning event to the Hillbrow tower taken by the South African photographer Jonathan Wood.

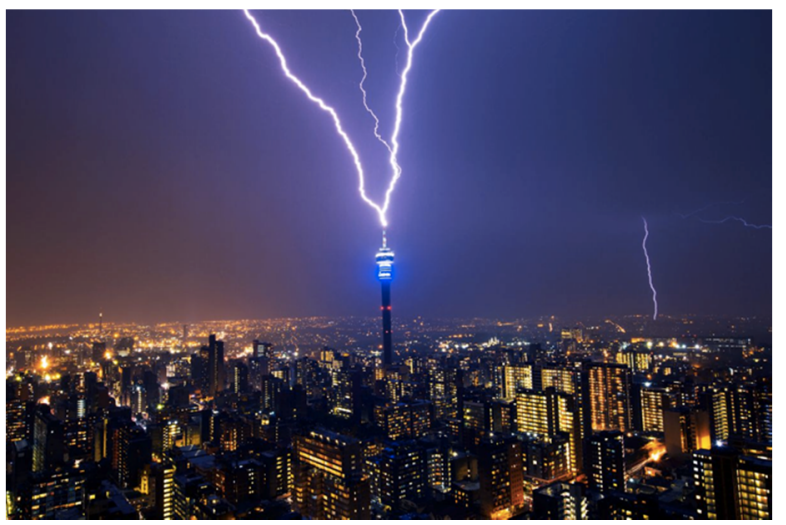

Figure 9. Photograph lightning event to Hillbrow tower taken from the Ponte building. Courtesy Jonathan Wood.

These simple surveillance camera setups provide additional information to the high-speed video observations, giving a different perspective on the channel and allowing for identification of strike-points that may not have been visible from the high-speed footage.

\section{Methodology}

For the end of the season (January - May 2017) and the following season (October 2017 - May 2018), the high-speed camera setup and surveillance camera setup were activated and capturing video footage of lightning during thunderstorm over South Africa. 
For each filmed lightning flash, the following categorizations were performed based on the video:

- Downward flashes

- Continuing current duration

- Polarity

- Multiplicity

- Multiple strike points

- Total flash duration

- Upward flashes

- Triggering events

- Duration and continuing current

- Polarity

- Subsequent return strokes

- ICC pulses

- Tall towers involved

Also discussed in the analysis are a number of bipolar events observed by the camera. Upward and downward events are categorized based on the direction of propagation of the leader. Polarity is determined based on the presence of branching and recoil leaders.

\section{FIRST RESULTS: 2017 - 2018}

During this first year of high-speed video recording in Johannesburg, 168 downward flashes were recorded. Upward flashes also were observed from Johannesburg towers and tall buildings. A total of 45 upward flashes were registered. Table 2 shows a summary of the lightning events captured by highspeed video over Johannesburg from February 2017 to February 2018.

TABLE II. NUMBER OF Flashes RECORDED FEB 2017-2018

\begin{tabular}{|c|c|c|}
\hline \multicolumn{2}{|c|}{ Type } & Quantity \\
\hline \multirow{2}{*}{ Downward } & Negative & 155 \\
\cline { 2 - 3 } & Positive & 6 \\
\hline \multirow{2}{*}{ Upward } & Negative & 43 \\
\cline { 2 - 3 } & Positive & 2 \\
\hline \multicolumn{2}{|c|}{ Triggering events } & 6 \\
\hline \multicolumn{2}{|c|}{ Bi-polar } & 1 \\
\hline \multicolumn{2}{|c|}{ Total } & 262 \\
\hline
\end{tabular}

\section{A. Downward flashes}

A total of 155 negative downward flashes, 6 positive downward flashes and 1 bipolar downward flash were recorded. A bipolar flashes was considered only when a channel was used to transfer different polarities of charge. In addition to this amount, 6 downward flashes were classified as triggering flashes due to the occurrence at the same time and framed in the same camera view of upward flashes. These triggering flashes were observed to be 5 positive downward flashes and 1 bipolar flash.
The number of strokes and statistics for the duration of each flash consider all registered downward strokes, including triggering events. A total of 605 negative strokes and 13 positive strokes were recorded. Figure 10 shows a frame taken for a high-speed video of a downward flash over Johannesburg. Table III summarizes the characteristics of the downward flashes recorded over Johannesburg.

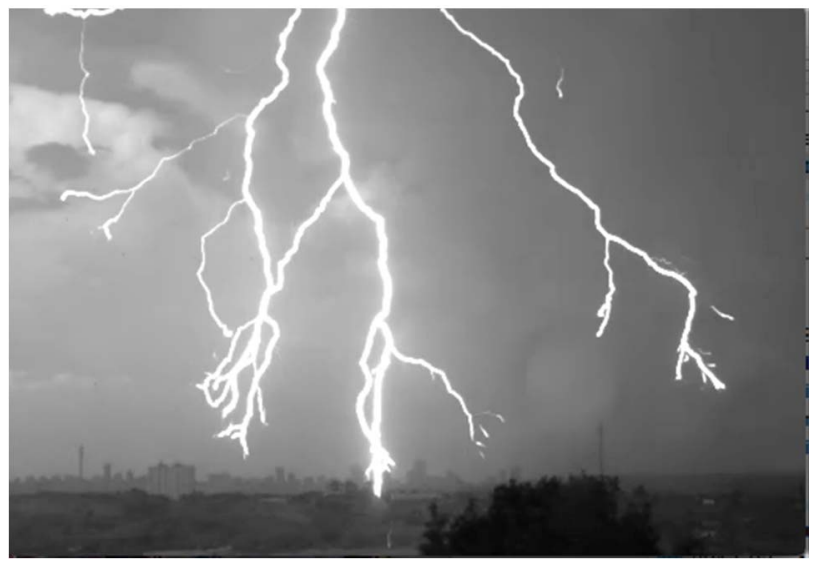

Figure 10. Frame taken from high-speed video of downward lightning over Johannesburg, South Africa.

The two bipolar flashes began with a single positive stroke followed by 2 and 3 negative strokes respectively. The strokes followed the same channel and attached to the same strike point. The bipolar flash that had 4 strokes, triggered an upward leader from the Brixton tower 2 kilometers from the downward strike point. The upward leader started after the positive stroke and the following 3 negative strokes happened during the continuous current of the upward leader. Both bipolar flashes follow the same structure as that seen by Saba et al. [8].

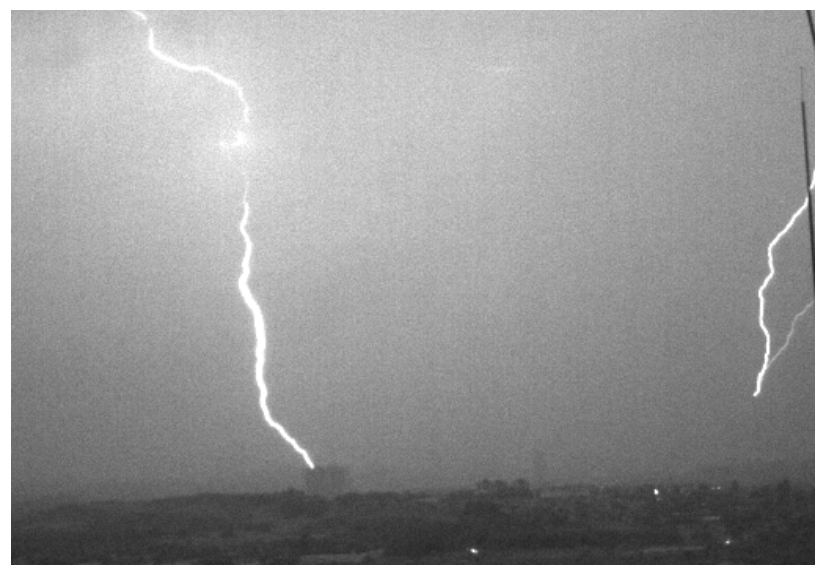

Figure 11. Downward bipolar flash struck the building and triggered an upward leader from a 250 meter-tower 2 kilometer away.

TABLE III. DOWNWARD FLASH STROKES

\begin{tabular}{|l|c|c|c|c|}
\cline { 2 - 5 } \multicolumn{1}{c|}{} & N & AM & Min & Max \\
\hline NEGATIVE FLASHES & 155 & & & \\
\hline Max Number of Strike Points & 3 & & & \\
\hline $\begin{array}{l}\text { Multiplicity - Average of Strokes } \\
\text { per flash }\end{array}$ & & 3,1 & 1 & 26 \\
\hline
\end{tabular}




\begin{tabular}{|l|c|c|c|c|}
\hline Max Duration Negative strokes & 605 & 28,7 & 1 & 929 \\
\hline Time between Strokes (ms) & 460 & 66,5 & 6 & 546 \\
\hline Time with no current (ms) & 425 & 43,3 & 2 & 360 \\
\hline Total duration (ms) & 206 & 320,4 & 2 & 1162 \\
\hline
\end{tabular}

\begin{tabular}{|l|c|c|c|c|}
\hline POSITIVE FLASHES & N & AM & Min & Max \\
\hline Positive strokes & 6 & & & \\
\hline $\begin{array}{l}\text { Max Duration Positive strokes* } \\
\text { (*Including bipolar and } \\
\text { triggering events) }\end{array}$ & 13 & 230 & 2 & 567 \\
\hline
\end{tabular}

As presented by Kitagawa et al. [9], Brook et al. [10] Shindo and Uman [11], Ballarotti et al. [12] the continuous current can be defined by the duration and the terms are "very short" for durations from $3 \mathrm{~ms}$ up to $10 \mathrm{~ms}$, "short" for durations between $10 \mathrm{~ms}$ up and $40 \mathrm{~ms}$ and "long" for cases where the duration is more than $40 \mathrm{~ms}$. The continuous current duration for negative and positive strokes is presented in Table IV.

TABLE IV. CONTINUOUS CURRENT DURATION

\begin{tabular}{|l|c|c|}
\cline { 2 - 3 } \multicolumn{1}{c|}{} & $\begin{array}{c}\text { Negative } \\
\text { Strokes }\end{array}$ & $\begin{array}{c}\text { Positive } \\
\text { Strokes }\end{array}$ \\
\cline { 2 - 3 } \multicolumn{1}{c|}{} & 605 & 13 \\
\hline Number of strokes without CC & 108 & 1 \\
\hline CC Very short $3>C C>10$ & 264 & 1 \\
\hline CC Short $10>C C>40 \mathrm{~ms}$ & 160 & 0 \\
\hline CC Long more than $40 \mathrm{~ms}$ & 73 & 11 \\
\hline
\end{tabular}

\section{B. Upward Flashes}

From a total of 43 upward flashes that were recorded, 41 were negative upward flashes and 2 were positive upward flashes. Negative upward flashes are the flashes that transfer negative charge to the ground, i.e. the upward positive leader propagates toward to the cloud. The image obtained from the high-speed camera shows a leader with no branches. On the other hand, positive upward flashes have branched negative upward leaders propagating towards the cloud. Figure 12 shows the two types of upward leader: a) positive and nobranched upward leader and b) negative and branched upward leader.
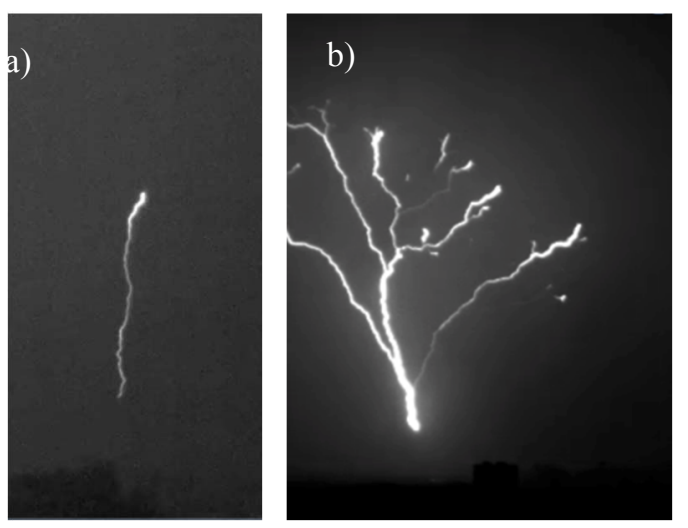

Figure 12. Frames taken from high-speed video of (a) positive upward leader (negative upward flash) and (b) negative upward leader (Positive upward flash)
Upward flashes were recorded mainly from the Brixton and Hillbrow tower. For the multiple tower-involved cases, 10 out of 11 had both towers producing upward leaders $(4.8 \mathrm{~km}$ from each other), one case had three upward leaders from both towers and also the SABC building (115-meter building). One other case involved a $90 \mathrm{~m}$ tall tower $2.5 \mathrm{~km}$ from the Hillbrow tower and the Hillbrow tower.

Upward flashes start with an upward leader propagation that is known in the literature as a Initial Continuous Current (ICC), any fluctuation of luminosity in this stage are designated as ICC pulses. After this stage the upward flash can end or, after some tens of milliseconds, a downward leader can use the ionized channel to transfer charge to the ground (Return Stroke). These return strokes can then be followed by continuous current. The luminosity of upward flashes can be summarized as in the figure 13.

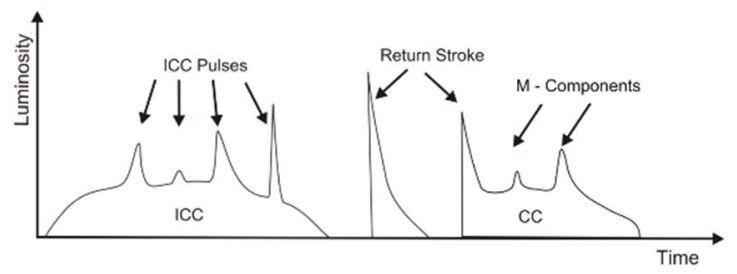

Figure 13. Upward flash luminosity profile (Saba et al. 2016)

The average and maximum duration of upward initial continuous current stages were $405 \mathrm{~ms}$ and $990 \mathrm{~ms}$ respectively. 398 pulses were registered in the 41 negative upward flashes. Table V shows some of the characteristics of the upward flashes filmed over Johannesburg.

TABLE V. NeGATIVE UpWARD FLASH

\begin{tabular}{|l|c|}
\hline Negative upward flashes & 41 \\
\hline Negative Leaders & 53 \\
\hline w/ multiple tower involved & 11 \\
\hline Max duration ICC & $990 \mathrm{~ms}(\mathrm{AM}=405 \mathrm{~ms})$ \\
\hline ICC Pulses (N) & 398 \\
\hline RS in negative upward flash $(\mathrm{N})$ & 38 \\
\hline Max Duration RS Triggering event: \\
\hline \multicolumn{2}{|c|}{$269(\mathrm{AM}=28 \mathrm{~ms})$} \\
\hline W/ triggering event visible: & 6 \\
\hline Positive Flashes & 5 \\
\hline Bipolar flashes (+CG $>$ UP $>-C G)$ & 1 \\
\hline
\end{tabular}

\section{Potential current measurement:}

A number of lightning events were observed attaching to a $53 \mathrm{~m}$ tall apartment building (Figure 14). From the SALDN and videos, this building was struck by positive, negative and bipolar downward flashes. 

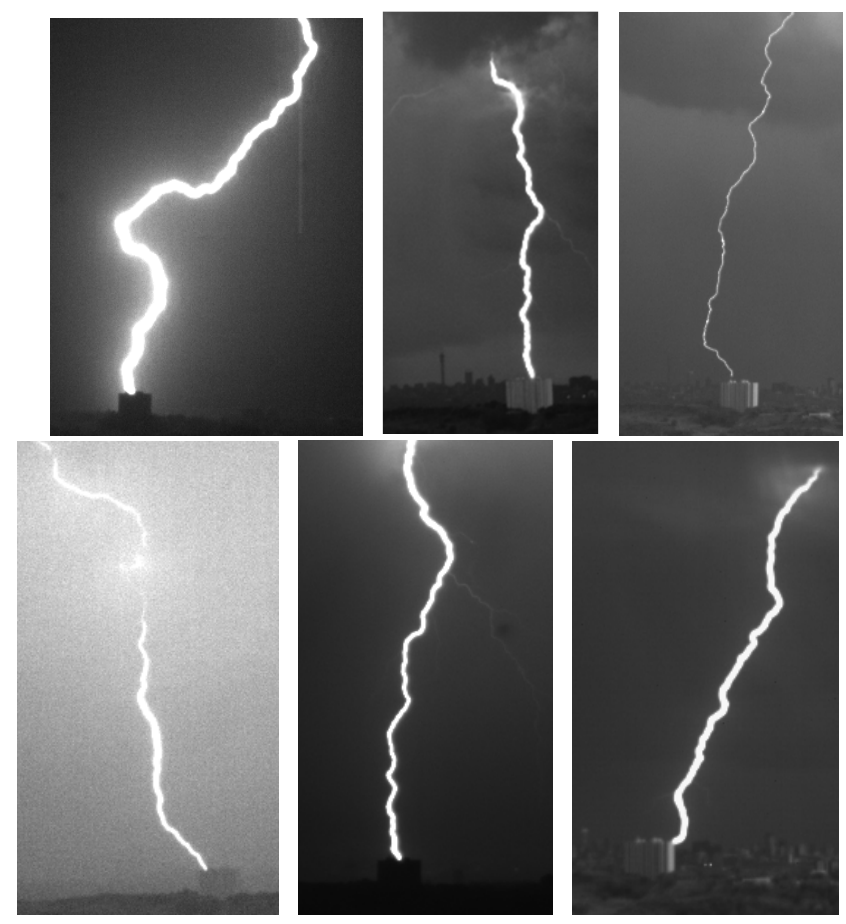

\section{SUMMARY}

The Johannesburg scientific project aims to investigate the physics of lightning by high-speed video observation along with electric field measurements. All equipment and collaborations available were presented. Previous studies about the location were also provided.

A total of 168 downward flashes and 43 upward flashes were characterized. Characteristics of 13 positive and 605 negative strokes and 41 negative upward flashes were presented. Flashes with almost 1 second connected to ground: negative downward flash (929ms) and upward flash (990ms).

One building in particular presented an ideal location to install a current system for natural downward flash measurement. Towers approximately 250 meters-tall and $4.8 \mathrm{~km}$ from each also are potential locations for the installation of a current measurement system due to number of upward flashes. The current system combined with high-speed video and the high cloud base in Johannesburg would provide more information about the initiation of flashes.

\section{ACKNOWLEDGMENT}

The author Carina Schumann would like to thank the Claude Leon Foundation for the Post-doctoral fellowship. The authors also like to thank South African Weather Service (SAWS) for their support and for providing the SALDN data used in this paper. They would also like to thank Eskom for the support of the Lightning/EMC Research Group through the TESP programme. Thanks are extended to the Department of Trade and Industry (DTI) for THRIP funding as well as to the National Research Foundation (NRF) for direct funding of the Research Group.

\section{REFERENCES}

[1] Eriksson, A.J. (1978), Lightning and tall structures, Transactions: The SA Institute of Electrical Engineering, pp. 238-252.

[2] Anderson, R.B. and A. J. Eriksson (1980), Lightning parameters for engineering application.Electra Vol.69, 65-102, 1980.

[3] Gijben M. The lightning climatology of South Africa. S Afr J Sci. 2012;108(3/4), Art. \#740, 10 pages.

[4] H.G.P Hunt, K.J. Nixon and I.R. Jandrell: "Establishing a methodology to investigate LDN median error ellipses used as corroborating evidence for a lightning event at a specific geographic locations." Electric Power Systems Research Journal, 2014.

[5] T.A. Warner, K.L. Cummins and R.E. Orville: "Upward lightning observations from towers in Rapid City, South Dakota and comparison with National Lightning Detection Network data, 2004-2010”, Journal of Geophysical Research, Res. 117, D19109, doi:10.1029/2012JD018346

[6] M.M.F. Saba, M.G. Ballarotti, O. Pinto, Jr: "Negative cloud-to-ground lightning properties from high-speed video observations." Journal of Geophysical Research, vol. 111, p. D03101, 2006.

[7] M.M.F. Saba, W. Schulz, T.A. Warner, L.Z.S. Campos, K.L. Cummins, R.E. Orville: "High-speed video observations of positive lightning flashes to ground." Journal of Geophysical Research: Atmospheres, vol. 115, p. D24201, 2010.

[8] M.M.F. Saba, C. Schumann, T.A Warner, J.H. Helsdon, W. Schulz, R.E Orville: "Bipolar cloud-to-ground lightning flash oberservations." Journal of Geophysical Research: Atmospheres, vol. 118, p. 1-9, 2013.

[9] N. Kitagawa, M. Brook, E.J. Workman, -Continuing currents in cloudto-ground lightning discharges, J. Geophys. Res. 67, pp. 637-647, 1962.

[10] M. Brook, N. Kitagawa, E.J. Workman, —Quantitative study of strokes and continuing currents in lightning discharges to ground, J. Geophys. Res. 67, pp. 649-659, 1962.

[11] T. Shindo, M.A. Uman, -Continuing current in negative cloud- toground lightning, J. Geophys. Res. 94, pp. 5189-5198, 1989.

[12] M.G. Ballarotti, M.M.F. Saba, O. Pinto Jr., - High-speed camera observations of negative ground flashes on a millisecond-scale. Geophys. Res. Lett. 32, L23802.doi:10.1029/2005GL023889, 2005. 